\title{
Meta-analysis of the clinical characteristics and prognostic relevance of NOTCH1 and FBXW7 mutation in T-cell acute Iymphoblastic leukemia
}

\author{
Rong-Bin Liu ${ }^{1,2,3, *}$, Jian-Gui Guo ${ }^{1,2,4,8, *}$, Tian-Ze Liu ${ }^{1,2, *}$, Cheng-Cheng Guo ${ }^{1,2,5}$, \\ Xin-Xiang Fan', Xiao Zhang ${ }^{1,2,3}$, Wei-Han $\mathrm{Hu}^{1,2,4}$ and Xiu-Yu Cai ${ }^{1,2,7}$ \\ ${ }^{1}$ State Key Laboratory of Oncology in South China, Guangzhou, China \\ ${ }^{2}$ Collaborative Innovation Center for Cancer Medicine, Guangzhou, China \\ ${ }^{3}$ Department of Molecular Diagnostics, Sun Yat-Sen University Cancer Center, Guangzhou, China \\ ${ }^{4}$ Department of Radiation Oncology, Sun Yat-Sen University Cancer Center, Guangzhou, China \\ ${ }^{5}$ Department of Neurosurgery, Sun Yat-Sen University Cancer Center, Guangzhou, China \\ ${ }^{6}$ Department of Urology, Sun Yat-Sen Memorial Hospital, Guangzhou, China \\ ${ }^{7}$ Department of VIP Region, Sun Yat-Sen University Cancer Center, Guangzhou, China \\ ${ }^{8}$ Department of Radiation Oncology, The First People's Hospital of Foshan, Foshan, China \\ *These authors contributed equally to this work \\ Correspondence to: Xiu-Yu Cai, email: caixy@sysucc.org.cn \\ Wei-Han Hu, email: huwh@sysucc.org.cn
}

Keywords: $T$-ALL, NOTCH1, FBXW7, prognosis, meta-analysis

Received: September 20, $2016 \quad$ Accepted: April 26, $2017 \quad$ Published: June 19, 2017

Copyright: Liu et al. This is an open-access article distributed under the terms of the Creative Commons Attribution License 3.0 (CC BY 3.0 ), which permits unrestricted use, distribution, and reproduction in any medium, provided the original author and source are credited.

\section{ABSTRACT}

The NOTCH1 signaling pathway is crucial for T-cell development, and NOTCH1 and/or FBXW7 mutations are frequently detected in T-cell acute lymphoblastic leukemia (T-ALL). We performed a systematic review and meta-analysis of 18 randomized controlled trials (RCTs) to assess the prognostic impact of mutations in the NOTCH1 pathway. After retrieving relevant articles from PubMed, EMBASE, and the Cochrane Library, we investigated overall survival (OS) and event-free survival (EFS) with hazard ratios (HRs) using fixed-effects or random-effects models and conducted subgroup analyses based on population and mutation status. NOTCH1/ FBXW7 mutations correlated significantly with better prognosis (5-year EFS: HR, 0.57; $95 \%$ confidence interval $[\mathrm{CI}], 0.46$ to $0.68 ; P<0.001$ and 5 -year OS: $\mathrm{HR}, 0.61 ; 95 \% \mathrm{CI}$, 0.51 to $0.74 ; P<0.001)$. The HR for 5 -year EFS and OS with NOTCH1 mutations were $0.63(95 \% \mathrm{CI}, 0.53$ to 0.75$)$ and $0.76(95 \% \mathrm{CI}, 0.60$ to 0.95$)$, respectively; with FBXW7 mutations, they were 0.82 (95\% CI, 0.60 to 1.11$)$ and 0.79 (95\% CI, 0.55 to 1.12), respectively. However, differences between children and adults showed no significance. We conclude that the presence of NOTCH1/FBXW7 mutations is an independent prognostic factor for 5-year EFS and 5-year OS.

\section{INTRODUCTION}

T-cell acute lymphoblastic leukemia (T-ALL) accounts for approximately $15 \%$ and $25 \%$ of ALL in pediatric and adult patients, respectively [1], and is clinically characterized as a high-risk malignancy with a relapse rate of approximately $30 \%$ [2]. This disease is commonly correlated with acquired chromosomal translocations and other genetic or epigenetic abnormalities, leading to aberrant expression of a series of transcription factors [3]. Most of the chromosome rearrangements involve NOTCH1, which is constitutively active because of $\mathrm{t}(7 ; 9)$ (q34:q34.3) activating mutations, also known as Notch homolog 1 and translocation-associated Drosophila, human genes encoding single-pass transmembrane receptor. Mutations in the NOTCH1 gene are the most common genetic abnormalities found in T-ALL, affecting more than $50 \%$ of patients $[4,5]$. Mutations affect two 
domains - the extracellular heterodimerization domain (HD), where mutations lead to ligand-independent cleavage, and the C-terminal proline, glutamic acid, serine, and threonine (PEST)-rich domain truncating mutations [6]. Weng et al. [3] demonstrated activation of NOTCH1 mutations in more than $50 \%$ of pediatric T-ALL patients. Aberrant NOTCH1 signaling was originally linked to the pathogenesis of T-ALL by the cloning of the $\mathrm{t}(7 ; 9)$ (q34; q34.3) chromosomal translocation, which leads to the expression of a truncated and constitutively active form of NOTCH1. The $\gamma$-secretase inhibitors (GSIs), which block the proteolytic cleavage of the NOTCH receptors and suppress the release of activated NOTCH1 (ICN1) from the membrane, have been proposed as a potential therapy in T-ALL. Moreover, F-box and WD-40 domain protein 7 (FBXW7) promotes proteasome degradation in activated NOTCH1. FBXW7 is an E3 ubiquitin ligase that recognizes the PEST domain of ICN1 and accelerates the termination of NOTCH1 signaling in the nucleus [7]. Hence, NOTCH1 mutations, FBXW7 mutations, or both lead to activation of the NOTCH1 pathway [8]. Studies have examined the correlation between NOTCH1/FBXW7 status and T-ALL. However, the outcome and results are inconsistent [9-19], and the impact of NOTCH1/FBXW7 mutations on long-term outcome in T-ALL patients is still undetermined [20].

In this meta-analysis, we investigated the relevance of NOTCH1 mutations, FBXW7 mutations, or both in relation to long-term prognosis.

\section{RESULTS}

\section{Study characteristics}

Trials were classified into three subgroups, NOTCH1 alone, FBXW7 alone, and NOTCH1/FBXW7, because NOTCH1 and FBXW7 belong to the same signaling pathway. In each group, children and adults were analyzed. Patients younger than 18 years were assigned to the child group. Patients older than 18 years were assigned to the adult group. Overall survival (OS) was defined as the time from diagnosis to death by any cause or to last followup. Event-free survival (EFS) was defined as the time from diagnosis to the date of last follow-up in complete remission or first event. Events were resistance to therapy (non-response), relapse, secondary neoplasm or death by any cause. Failure to achieve remission because of early death or non-response was considered an event at time zero.

\section{NOTCH1 and FBXW7 mutations}

A total of 866 patients were screened for both NOTCH1 and FBXW7 mutations in 12 trials [9-19, 21]. Details are shown in Table 1. Based on age, all patients were divided into an adult subgroup and a child subgroup.

\section{5-year overall survival}

We analyzed the 5-year OS of all patients and found that two trials did not include this value. We eliminated those trials when performing the analysis. The pooled HR from the remaining trials was 0.61 (95\% CI, 0.51-0.74; $P<0.00001)$. HR of the child subgroup was $0.60(95 \% \mathrm{CI}$, $0.42-0.87 ; P=0.007)$. HR of the adult subgroup was 0.62 (95\% CI,0.50-0.77; $P<0.00001)$. As the high degree of heterogeneity was performed, the HR of the adult subgroup was not sufficient (Figure 1A). We concluded that NOTCH1 and FBXW7 mutations were correlated with a better survival in T-ALL pediatric patients.

\section{5-year event-free survival}

One adult study did not include the relevant statistics for 5-year EFS. We eliminated that study. The pooled HR of the remaining studies was 0.57 (95\% CI, 0.48-0.67; $P<0.00001)$. In the child subgroup, HR was $0.59(95 \% \mathrm{CI}$, $0.43-0.81 ; P=0.00009)$. In the adult subgroup, HR was 0.56 (95\% CI, 0.46-0.68; $P<0.00001)$. Figure 1B shows that T-ALL patients who harbored NOTCH1 and FBXW7 mutations had a better prognosis than those who did not. Mutations in the child subgroup were not significantly different from those in the adult subgroup.

\section{NOTCH1 mutation}

A total of 826 T-ALL patients from 16 trials [9-12, 16, 17, 21-27] had NOTCH1-type mutation. Details were shown in Table 2 . We divided the 826 patients into a child subgroup and an adult subgroup by the age. Six trials did not provide information about OS. In Callens et al. [28], patients' total survival periods were up to 4 years. Two trials did not provide patients EFS information. We eliminated those trials. The pooled HRs for 5-year OS and 5-year EFS from all the patients were, respectively, 0.76 (95\% CI, $0.56-0.95 ; P=0.02$ ) and 0.63 (95\% CI, 0.53-0.75; $P<0.00001)$. For the child subgroups, relevant HR, 5-year OS, and 5-year EFS were 0.63 (95\% CI, 0.42-0.94; $P=0.02)$ and 0.57 (95\% CI, 0.45-0.72; $P<0.00001)$. For the adult subgroups, relevant HR, 5-year OS, and 5-year EFS were $0.83(95 \% \mathrm{CI}, 0.62-1.10 ; P=0.19)$ and $0.71(95 \% \mathrm{CI}, 0.55-0.92 ; P=0.010)$. Figure $2 \mathrm{~A}$ and $2 \mathrm{~B}$ show that these outcomes are a more favorable survival indication for NOTCH1 mutation-positive patients than for NOTCH1 mutation-negative patients. When compared with adult patients, child patients had a better prognosis.

\section{FBXW7 mutations}

A total of 197 T-ALL patients in 9 trials [9, 11, 12, $16,17,21,24,25]$ harbored only the FBXW7 mutation. Details are shown in Table 3. The 5-year EFS and OS for 10 reports analyzed for FBXW7 mutation status (7 reports 
Table 1: Summary of 12 trials of NOTCH1/FBXW7 mutations included in this meta-analysis

\begin{tabular}{|c|c|c|c|c|c|c|c|}
\hline \multirow{2}{*}{ Source [Reference] } & \multirow{2}{*}{ Country } & \multirow{2}{*}{ Age } & \multirow{2}{*}{ Protocols/Trials } & \multirow{2}{*}{$\begin{array}{l}\text { Study } \\
\text { groups }\end{array}$} & \multirow{2}{*}{$\begin{array}{l}\text { No. of } \\
\text { patients }\end{array}$} & \multicolumn{2}{|c|}{ No. of events } \\
\hline & & & & & & OS & EFS \\
\hline \multirow[t]{2}{*}{ Bonn et al (2013) } & USA & Child & NHL-BFM & Mut & 74 & na & 62 \\
\hline & & & & WT & 42 & na & 28 \\
\hline \multirow[t]{2}{*}{ Clappier et al (2010) } & Finland & Child & EORTC58951 & Mut & 80 & 31 & 26 \\
\hline & & & & WT & 54 & 18 & 16 \\
\hline \multirow[t]{2}{*}{ Erbilgin et al (2010) } & Turkey & Child & ALL-BFM protocols & Mut & 20 & 15 & 16 \\
\hline & & & & WT & 67 & 39 & 54 \\
\hline \multirow[t]{2}{*}{ Fogelstrand et al (2014) } & Sweden & Child & $\begin{array}{l}\text { NOPHO ALL-1992 and } \\
\text { ALL-2000 }\end{array}$ & Mut & 47 & 22 & 28 \\
\hline & & & & WT & 32 & 17 & 14 \\
\hline \multirow[t]{2}{*}{ Jenkinson et al (2013) } & UK & Child & MRC UKALL 2003 & Mut & 101 & 37 & 36 \\
\hline & & & & WT & 57 & 16 & 15 \\
\hline \multirow[t]{2}{*}{ Myoung-Ja et al (2008) } & Japan & Child & $\begin{array}{l}\text { (JACLS) protocols ALL- } \\
97\end{array}$ & Mut & 22 & 22 & 21 \\
\hline & & & & WT & 33 & 26 & 23 \\
\hline \multirow[t]{2}{*}{ Abdelali et al (2010) } & France & Adult & LALA-94 and GRAALL & Mut & 159 & 25 & 21 \\
\hline & & & & WT & 73 & 4 & 4 \\
\hline \multirow[t]{2}{*}{ Baldus et al (2009) } & Germany & Adult & GMALL $05 / 93$ and $06 / 99$ & Mut & 67 & na & 28 \\
\hline & & & & WT & 33 & na & 9 \\
\hline \multirow[t]{2}{*}{ Mansour et al (2009) } & UK & Adult & $\begin{array}{l}\text { UKALLXII/ECOGE2993 } \\
\text { protocol }\end{array}$ & Mut & 58 & 11 & 11 \\
\hline & & & & WT & 30 & 4 & 3 \\
\hline \multirow[t]{2}{*}{ Mansur et al (2012) } & Brazil & Adult & BFM protocols & Mut & 62 & 36 & 25 \\
\hline & & & & WT & 48 & 23 & 23 \\
\hline \multirow[t]{2}{*}{ Trinquand et al (2013) } & France & Adult & $\begin{array}{l}\text { GRAALL-2003; } \\
\text { GRAALL-2005 }\end{array}$ & Mut & 143 & 39 & 34 \\
\hline & & & & WT & 69 & 8 & 7 \\
\hline \multirow[t]{2}{*}{ Vlierberghe et al (2013) } & USA & Adult & E2993 ECOG & Mut & 33 & 19 & na \\
\hline & & & & WT & 20 & 5 & na \\
\hline
\end{tabular}

Abbreviations: WT, wild type; Mut, mutational status; OS: overall survival at 5 years; PFS: progression-free survival at 5 years. NA indicates not available.

for 5-year OS and 9 reports for 5-year EFS). The totalpatients group $(n=431)$, had a 5 -year OS of $\mathrm{HR}=0.79$ (FBXW7 mutations status vs wild-type FBXW7, $P=0.19$ ). The total-patients group $(n=848)$ had a 5 -year EFS of $\mathrm{HR}=0.82$ (FBXW7 mutations status vs wild-type FBXW7, $P=0.19)$. In the studies of children, the totalpatients group $(n=220)$ had a 5 -year OS of $\mathrm{HR}=0.60$ (FBXW7 mutations status vs wild-type FBXW7, $P=0.13)$. The total-patients group $(n=637)$ had a 5 -year EFS of HR $=0.86$ (FBXW7 mutations status vs wildtype FBXW7, $P=0.43)$. In the adult subgroup, the totalpatients group $(n=211)$ had a 5-year OS of HR $=0.88$ (FBXW7 mutations status vs wild-type FBXW7, $P=0.54)$. The total-patients group $(n=211)$ had a 5 -year
EFS of HR $=0.74$ (FBXW7 mutations status vs wildtype $\mathrm{FBXW7}, P=0.26$ ). On the basis of the primary data demonstrated in Figure 3A and 3B

we concluded that the FBXW7 mutation did not have a significant effect on the prognosis of the child patients and the adult patients.

In general, concurrent NOTCH1 and FBXW7 mutations were associated with a better patient survival than the NOTCH1 mutations.

\section{Heterogeneity analysis and publication}

Heterogeneity, which correlated with the pooled OS and EFS HRs, was not distinct because the values were all 
less than $50 \%$. Six funnel plots were almost symmetrical, indicating no obvious publication bias existed in our metaanalysis (Supplementary Figure 2).

\section{DISCUSSION}

Ma et al. [29] carried out a literature-based metaanalysis that focused on the effect of NOTCH1 expression for the prognosis of T-ALL and found no beneficial effects on EFS in the NOTCH1 mutations subgroup. However, these original results are incomplete and the lack of a systematic review evaluation failed to give further insights on this issue. In our meta-analysis, we found that T-ALL patients with NOTCH1 mutations alone or in combination with FBXW7 have a better prognosis compared with those without FBXW7 mutations, without NOTCH1 mutations, or both, especially in the NOTCH1/FBXW7 subgroup. The statistically significant association with 5-year OS and EFS was detected in our study. We found that NOTCH1/FBXW7 mutations significantly increased the risk of long-term prognosis. Furthermore, the HR for 5 -year EFS and OS in patients with NOTCH1 mutations were $0.63(95 \% \mathrm{CI}, 0.53$ to 0.75$)$ and 0.76 (95\% CI, 0.60 to 0.95$)$, and the HR for 5-year EFS and OS in patients with FBXW7 mutations were 0.82 (95\% CI, 0.60 to 1.11 ) and $0.79(95 \% \mathrm{CI}, 0.55$ to 1.12$)$. In all T-ALL patients in

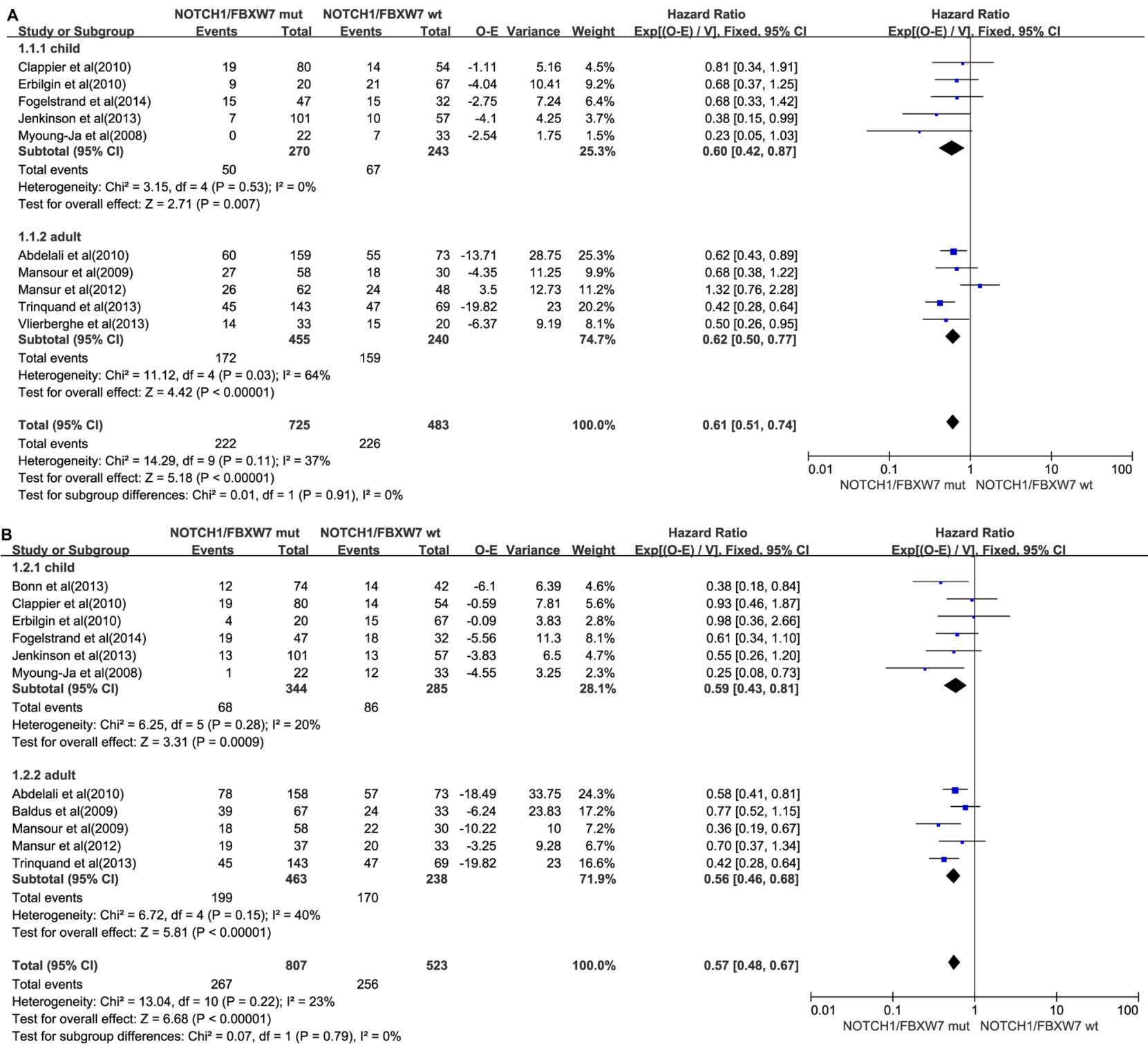

Figure 1: NOTCH1/FBXW7 mutations group. (A) Forest plot of hazard ratio (HR) of 5-year overall survival. (B) Forest plot of hazard ratio (HR) of 5-year progression-free survival. The estimation of the HR of each individual trial corresponds to the middle of squares and the horizontal line gives $95 \%$ confidence interval. The closed diamond shows overall HR with its $95 \% \mathrm{CI}$. HR $<1$ and $95 \% \mathrm{CI}$, excluding 1 indicate improved survival for the NOTCH1/FBXW7 mutations status arm compared with the wild-type NOTCH1/FBXW7 arm. O-E, observed minus estimated number of death. V, variance. 
Table 2: Summary of 14 trials of NOTCH1 mutations only included in this meta-analysis

\begin{tabular}{|c|c|c|c|c|c|c|c|}
\hline \multirow{2}{*}{$\begin{array}{c}\text { Source } \\
\text { [Reference] }\end{array}$} & \multirow{2}{*}{ Country } & \multirow{2}{*}{ Age } & \multirow{2}{*}{ Protocols/Trials } & \multirow{2}{*}{ Study groups } & \multirow{2}{*}{$\begin{array}{c}\text { No. of } \\
\text { patients }\end{array}$} & \multicolumn{2}{|c|}{ No. of events } \\
\hline & & & & & & OS & EFS \\
\hline \multirow[t]{2}{*}{ Bonn et al (2013) } & USA & Child & NHL-BFM & Mut & 70 & na & 59 \\
\hline & & & & WT & 46 & na & 31 \\
\hline \multirow[t]{2}{*}{ Breit et al (2006) } & German & Child & ALL-BFM 2000 & Mut & 82 & na & 75 \\
\hline & & & & WT & 75 & na & 55 \\
\hline \multirow[t]{2}{*}{$\begin{array}{l}\text { Clappier et al } \\
(2010)\end{array}$} & Finland & Child & EORTC58951 & Mut & 80 & 63 & 58 \\
\hline & & & & WT & 54 & 44 & 38 \\
\hline \multirow[t]{2}{*}{$\begin{array}{l}\text { Erbilgin et al } \\
(2010)\end{array}$} & Turkey & Child & $\begin{array}{l}\text { ALL-BFM } \\
\text { protocols }\end{array}$ & Mut & 19 & 14 & 15 \\
\hline & & & & WT & 68 & 41 & 55 \\
\hline \multirow[t]{2}{*}{$\begin{array}{l}\text { Fogelstrand et al } \\
(2014)\end{array}$} & Sweden & Child & $\begin{array}{l}\text { NOPHO ALL- } \\
1992 ; 1992 ; \text { ALL- } \\
2000\end{array}$ & Mut & 45 & 27 & 26 \\
\hline & & & & WT & 34 & 17 & 16 \\
\hline \multirow[t]{2}{*}{ Gao et al (2014) } & China & Child & $\begin{array}{l}\text { BCH-2003 and } \\
\text { CCLG-2008 }\end{array}$ & Mut & 39 & na & 36 \\
\hline & & & & WT & 53 & na & 34 \\
\hline \multirow[t]{2}{*}{ Huh et al (2013) } & Korean & Child & NA & Mut & 9 & 1 & 1 \\
\hline & & & & WT & 7 & 0 & 0 \\
\hline \multirow[t]{2}{*}{ Kox et al (2010) } & German & Child & ALL-BFM 2000 & Mut & 150 & na & 112 \\
\hline & & & & WT & 151 & na & 130 \\
\hline \multirow[t]{2}{*}{$\begin{array}{l}\text { Myoung-Ja et al } \\
(2008)\end{array}$} & Japan & Child & $\begin{array}{l}\text { (JACLS) protocols } \\
\text { ALL-97 }\end{array}$ & Mut & 17 & 11 & 17 \\
\hline & & & & WT & 38 & 21 & 23 \\
\hline \multirow[t]{2}{*}{$\begin{array}{l}\text { Zuurbier et al } \\
(2010)\end{array}$} & German & Child & DCOG protocols & Mut & 42 & na & 32 \\
\hline & & & & WT & 29 & na & 16 \\
\hline \multirow[t]{2}{*}{$\begin{array}{l}\text { Zuurbier et al } \\
(2010)\end{array}$} & German & Child & COALL protocols & Mut & 39 & na & 25 \\
\hline & & & & WT & 35 & na & 22 \\
\hline \multirow[t]{2}{*}{$\begin{array}{l}\text { Asnafi et al } \\
(2010)\end{array}$} & France & Adult & $\begin{array}{l}\text { LALA-94; } \\
\text { GRAALL-2003 }\end{array}$ & Mut & 88 & 50 & 0 \\
\hline & & & & WT & 53 & 26 & 0 \\
\hline \multirow[t]{2}{*}{ Huh et al (2013) } & Korean & Adult & NA & Mut & 7 & 2 & 2 \\
\hline & & & & WT & 6 & 0 & 0 \\
\hline \multirow[t]{2}{*}{$\begin{array}{l}\text { Mansour et al } \\
(2009)\end{array}$} & UK & Adult & $\begin{array}{l}\text { UKALLXII/ } \\
\text { ECOGE2993 } \\
\text { protocol }\end{array}$ & Mut & 53 & 8 & 8 \\
\hline & & & & WT & 35 & 7 & 6 \\
\hline \multirow[t]{2}{*}{$\begin{array}{l}\text { Mansur et al } \\
(2012)\end{array}$} & Brazil & Adult & BFM protocols & Mut & 60 & 32 & 21 \\
\hline & & & & WT & 78 & 38 & 33 \\
\hline
\end{tabular}


the 18 trials, we determined the incidence of activating mutations. The incidence in NOTCH1/FBXW7 genes was $60.60 \%$. In addition, the number in NOTCH1 and FBXW7 genes was $51.11 \%$ and $22.38 \%$. When we studied the child and adult subgroups separately, we found that the mutation event rate was a little higher in the adult subgroup.

Previous research showed the prognostic effect of the NOTCH1 mutation was linked to the ages of the patients [30]. Because child patients respond well to current therapy, the significance of molecular biomarkers can be decreased by the relatively good prognosis in the child subgroup, and no significant superiority of survival time was observed in patients without NOTCH1 mutations. We conducted the stratified analysis by age to determine the correlation between NOTCH1 and FBXW7 gene mutations and T-ALL prognosis. In the subgroup analysis according to age, for 5-year EFS, no significant associations were found among adult and child subgroups. Evidence indicates that children with mutations status have better 5-year OS than adults. However, both in child

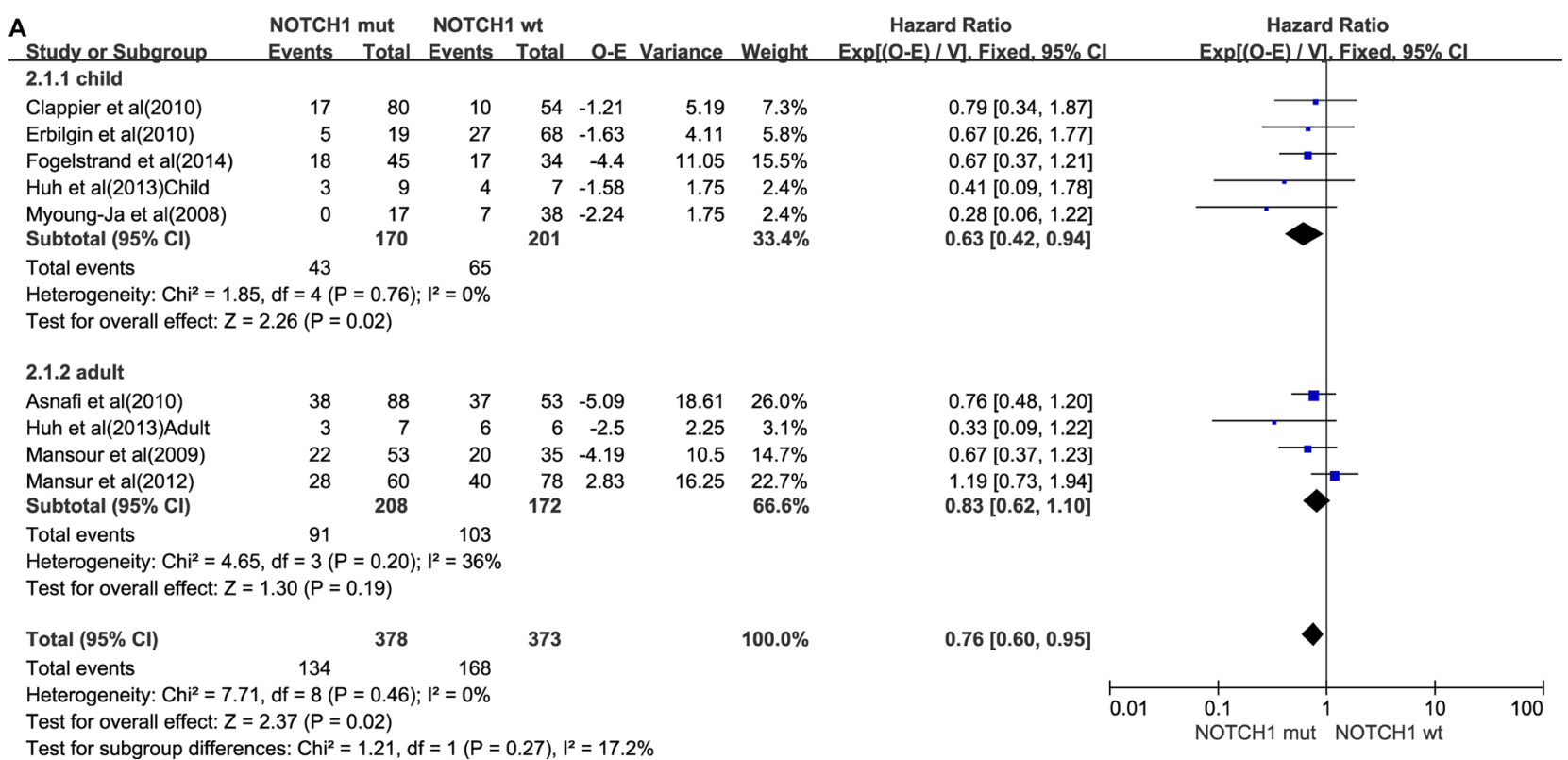

\begin{tabular}{|c|c|c|c|c|c|c|c|c|c|c|c|}
\hline B & $\begin{array}{l}\text { NOTCH } \\
\text { Events }\end{array}$ & $\begin{array}{l}\text { mut } \\
\text { Total }\end{array}$ & $\begin{array}{l}\text { NOTCH } \\
\text { Events }\end{array}$ & $\begin{array}{l}1 \text { wt } \\
\text { Total }\end{array}$ & O-E & Variance & Weight & $\begin{array}{c}\text { Hazard Ratio } \\
\text { Exp }(\mathrm{O}-\mathrm{E}) / \mathrm{V}] \text {. Fixed, } 95 \% \mathrm{Cl}\end{array}$ & $\begin{array}{r}\text { Hazard } \\
\operatorname{Exp}[(O-E) / V]\end{array}$ & $\begin{array}{l}\text { d Ratio } \\
\text { 1. Fixed, } 95 \% \mathrm{Cl}\end{array}$ & \\
\hline \multicolumn{12}{|l|}{2.2 .1 child } \\
\hline Bonn et al(2013) & 11 & 70 & 15 & 46 & -5.6 & 5.88 & $4.6 \%$ & $0.39[0.17,0.87]$ & & & \\
\hline Breit et al(2006) & 7 & 82 & 20 & 75 & -6.58 & 6.17 & $4.9 \%$ & $0.34[0.16,0.76]$ & & & \\
\hline Clappier et al(2010) & 22 & 80 & 16 & 54 & -1.09 & 12 & $9.4 \%$ & $0.91[0.52,1.61]$ & & & \\
\hline Erbilgin et al(2010) & 4 & 19 & 13 & 58 & 0.67 & 3.25 & $2.6 \%$ & $1.23[0.41,3.64]$ & & & \\
\hline Fogelstrand et al(2014) & 19 & 45 & 18 & 34 & -4.29 & 10.84 & $8.5 \%$ & $0.67[0.37,1.22]$ & $\longrightarrow$ & & \\
\hline Gao et al(2014) & 3 & 39 & 19 & 53 & -2.99 & 1.91 & $1.5 \%$ & $0.21[0.05,0.86]$ & & & \\
\hline Huh et al(2013)Child & 4 & 9 & 3 & 7 & -0.244 & 1.75 & $1.4 \%$ & $0.87[0.20,3.83]$ & & & \\
\hline Kox et al(2010) & 20 & 150 & 39 & 151 & -10.28 & 13.78 & $10.8 \%$ & $0.47[0.28,0.80]$ & 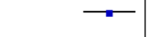 & & \\
\hline Myoung-Ja et al(2008) & 0 & 17 & 13 & 38 & -4.27 & 3.25 & $2.6 \%$ & $0.27[0.09,0.80]$ & & & \\
\hline Zuurbier et al(2010)COALL & 10 & 42 & 13 & 29 & -2.26 & 4.34 & $3.4 \%$ & $0.59[0.23,1.52]$ & & & \\
\hline Zuurbier et al(2010)DCOG & 12 & 39 & 14 & 35 & -2.26 & 6.1 & $4.8 \%$ & $0.69[0.31,1.53]$ & & & \\
\hline Subtotal $(95 \% \mathrm{Cl})$ & & 592 & & 580 & & & $54.5 \%$ & $0.57[0.45,0.72]$ & & & \\
\hline Total events & 112 & & 183 & & & & & & & & \\
\hline \multicolumn{12}{|c|}{ Heterogeneity: $\mathrm{Ch}^{2}=12.12, \mathrm{df}=10(\mathrm{P}=0.28) ; \mathrm{I}^{2}=17 \%$} \\
\hline \multicolumn{12}{|c|}{ Test for overall effect: $Z=4.71(P<0.00001)$} \\
\hline \multicolumn{12}{|l|}{ 2.2.2 adult } \\
\hline Asnafi et al(2010) & 62 & 88 & 27 & 53 & -7.67 & 19.88 & $15.6 \%$ & $0.68[0.44,1.06]$ & $\rightarrow$ & & \\
\hline Huh et al(2013)Adult & 3 & 7 & 6 & 6 & -2.62 & 2.25 & $1.8 \%$ & $0.31[0.08,1.15]$ & & & \\
\hline Mansour et al(2009) & 39 & 60 & 45 & 78 & -4.95 & 21 & $16.5 \%$ & $0.79[0.52,1.21]$ & - & & \\
\hline Mansur et al(2012) & 18 & 35 & 35 & 53 & -4.38 & 14.74 & $11.6 \%$ & $0.74[0.45,1.24]$ & 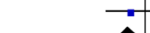 & & \\
\hline Subtotal $(95 \% \mathrm{Cl})$ & & 190 & & 190 & & & $45.5 \%$ & $0.71[0.55,0.92]$ & & & \\
\hline Total events & 122 & & 113 & & & & & & & & \\
\hline \multicolumn{12}{|c|}{ Heterogeneity: $\mathrm{Chi}^{2}=1.83, \mathrm{df}=3(\mathrm{P}=0.61) ; \mathrm{I}^{2}=0 \%$} \\
\hline \multicolumn{12}{|c|}{ Test for overall effect: $Z=2.58(P=0.010)$} \\
\hline Total $(95 \% \mathrm{Cl})$ & & 782 & & 770 & & & $100.0 \%$ & $0.63[0.53,0.75]$ & $\diamond$ & & \\
\hline Total events & 234 & & 296 & & & & & & & & \\
\hline \multicolumn{8}{|c|}{ Heterogeneity: $\mathrm{Chi}^{2}=15.56, \mathrm{df}=14(P=0.34) ; \mathrm{I}^{2}=10 \%$} & & & & \\
\hline $\begin{array}{l}\text { Test for overall effect: } Z=5 \text {. } \\
\text { Test for subgroup difference }\end{array}$ & $\begin{array}{l}2(P<0.00 \\
\mathrm{Chi}^{2}=1.6\end{array}$ & $\begin{array}{l}001) \\
2, d f=1\end{array}$ & 8.00 & 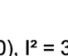 & 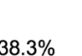 & & & 0.01 & $\begin{array}{l}0.1 \\
\text { NOTCH1 mut }\end{array}$ & $\begin{array}{r}1 \\
\text { NOTCH1 wt }\end{array}$ & 100 \\
\hline
\end{tabular}

Figure 2: NOTCH1 mutations group. (A) Forest plot of hazard ratio of 5-year overall survival. (B) Forest plot of hazard ratio of 5-year progression-free survival. 
Table 3: Summary of nine trials of FBXW7 mutations included in this meta-analysis

\begin{tabular}{|c|c|c|c|c|c|c|c|}
\hline \multirow{2}{*}{$\begin{array}{c}\text { Source } \\
\text { [Reference] }\end{array}$} & \multirow{2}{*}{ Country } & \multirow{2}{*}{ Age } & \multirow{2}{*}{ Protocols/Trials } & \multirow{2}{*}{ Study groups } & \multirow{2}{*}{$\begin{array}{c}\text { No. of } \\
\text { patients }\end{array}$} & \multicolumn{2}{|c|}{ No. of events } \\
\hline & & & & & & OS & EFS \\
\hline \multirow[t]{2}{*}{ Bonn et al (2013) } & USA & Child & NHL-BFM & Mut & 21 & na & 17 \\
\hline & & & & WT & 95 & na & 73 \\
\hline \multirow[t]{2}{*}{ Huh et al (2013) } & Korea & Child & NA & Mut & 4 & 1 & 1 \\
\hline & & & & WT & 12 & 0 & 0 \\
\hline \multirow[t]{2}{*}{ Kox et al (2010) } & Germany & Child & $\begin{array}{l}\text { ALL-BFM } 2000 \\
\text { study }\end{array}$ & Mut & 42 & na & 32 \\
\hline & & & & WT & 259 & na & 210 \\
\hline \multirow[t]{2}{*}{$\begin{array}{l}\text { Erbilgin et al } \\
(2010)\end{array}$} & Turkey & Child & $\begin{array}{l}\text { ALL-BFM } \\
\text { protocols }\end{array}$ & Mut & 7 & 6 & 7 \\
\hline & & & & WT & 64 & 41 & 45 \\
\hline \multirow[t]{2}{*}{$\begin{array}{l}\text { Fogelstrand et al } \\
(2014)\end{array}$} & Sweden & Child & $\begin{array}{l}\text { NOPHO ALL- } \\
1992 \text {; ALL-2000 }\end{array}$ & Mut & 18 & 14 & 12 \\
\hline & & & & WT & 57 & 16 & 15 \\
\hline \multirow[t]{2}{*}{$\begin{array}{l}\text { Myoung-Ja et al } \\
(2008)\end{array}$} & Japan & Child & $\begin{array}{l}(\mathrm{JACLS}) \\
\text { protocols ALL- } \\
97\end{array}$ & Mut & 8 & 8 & 5 \\
\hline & & & & WT & 47 & 40 & 22 \\
\hline \multirow[t]{2}{*}{ Huh et al (2013) } & Korea & Adult & NA & Mut & 4 & 1 & 1 \\
\hline & & & & WT & 9 & 1 & 1 \\
\hline \multirow[t]{2}{*}{$\begin{array}{l}\text { Mansour et al } \\
(2009)\end{array}$} & U K & Adult & $\begin{array}{l}\text { UKALLXII/ } \\
\text { ECOGE2993 }\end{array}$ & Mut & 72 & 2 & 2 \\
\hline & & & & WT & 16 & 10 & 9 \\
\hline \multirow[t]{2}{*}{$\begin{array}{l}\text { Mansur et al } \\
(2012)\end{array}$} & Brazil & Adult & BFM protocols & Mut & 21 & 13 & 12 \\
\hline & & & & WT & 89 & 46 & 37 \\
\hline
\end{tabular}

and in adult groups, the NOTCH1/FBXW7 mutations were correlated with a better 5-year EFS and 5-year OS. The presence of NOTCH1/FBXW7 mutations is a positive prognostic factor for T-ALL patient survival.

In the present meta-analysis, between-study heterogeneities for the overall data were absent in the six comparisons. Thus, the fixed-effect models were utilized. In the subgroup analyses, insignificant heterogeneities were also found in the relevant subgroups, increasing the stability and reliability of the results [31]. Several limitations should be addressed. First, the number of articles included was relatively small, especially for the FBXW7 group. Second, subgroup analyses with respect to treatment regimen, test methods, and other factors were not conducted in the present study because of the lack of relevant data in the primary literature. Third, some heterogeneity exists in the relation between mutations status and cancer prognosis. When the Calles article [28] was excluded, the heterogeneity disappeared. Despite the limitations, our meta-analysis indicated that T-ALL patients with concurrent NOTCH1 and FBXW7 mutations or a single NOTCH1 mutation had a significantly better survival than patients with wild-type FBXW7. So detecting mutation status by adopting molecular diagnosis could be an appropriate consideration. This method could be a beneficial therapeutic strategy.

\section{MATERIALS AND METHODS}

\section{Literature search strategy and study criterion}

A sensitive search strategy was developed for all English language literature published before May 2014. The comprehensive search was performed by use of the electronic databases PubMed, EMBASE, and the Cochrane Library. The search terms were T-cell acute lymphoblastic leukemia or T-ALL, NOTCH1, and FBXW7. The search was limited to randomized controlled trials or clinical 
trials. Meta-analysis articles were not excluded because several original studies were often combined in metaanalysis articles.

The selection criteria were as follows:

(a) All T-ALL patients were diagnosed by immunophenotypic analyses according to World Health Organization classification. (b) NOTCH1 and FBXW7 mutation were identified by direct sequencing of polymerase chain reaction-amplified products. (c) Case studies, review articles, and studies involving fewer than three patients were excluded. (d) Randomized controlled trials compared immunotherapy versus control therapy and included children and adults. (e) Adequate survival information and patterns of failure data were needed.

\section{Data extraction and quality control}

Two reviewers (RB. L and TZ. L) performed data extraction independently by use of standardized data extraction sheets. These data included study design, year of publication, population characteristics (country of patients and age), follow-up duration, trials, study groups, number of patients in each group and number of events in each group. Survival estimates were extracted directly from the text or deduced from the survival curve of the publication [32]. The principal summary measure was the hazard ratios (HRs), which could be extracted from the text or deduced from the original data. If the article did not provide the HRs for OS or event-free survival EFS,

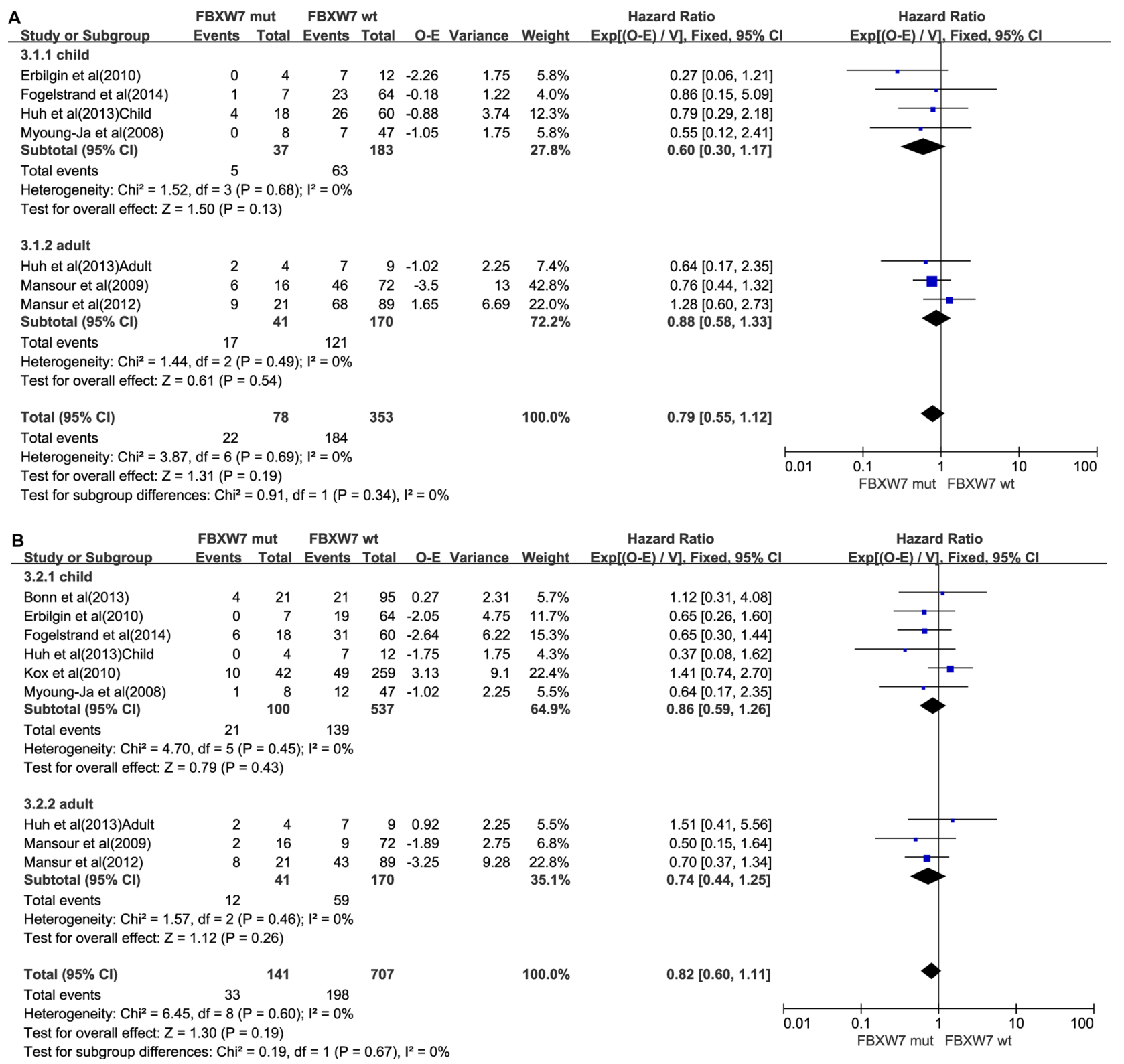

Figure 3: FBXW7 mutations group. (A) Forest plot of hazard ratio of 5-year overall survival. (B) Forest plot of hazard ratio of 5-year progression-free survival. 
the Engauge Digitizer Version 4.1 software was used to distinguish the survival curves and calculate the HRs of OS and EFS. We extracted the $P$ value of the log-rank test of the 5-year OS or the 5-year EFS.

To assign study quality, we examined the randomization procedure, estimation of sample size, allocation of concealment blinding of outcome assessor, loss to followup, dropout, and whether the intention-to-treat analysis was followed. The Jadad/Oxford quality scoring system was used to quantify study quality [33]. The study quality is shown in Supplementary Table 1. Any discrepancies in abstracting data were resolved by consensus.

\section{Data synthesis and analysis}

Considering that NOTCH1 and FBXW7 belong to the same signaling pathway, the trials were classified into three subgroups, NOTCH1 alone; FBXW7 alone; and NOTCH1, FBXW7, or both, based on the mutations status of T-ALL patients. Subgroup analyses of the end events were performed by utilization of HR to assess the differences between the mutations arm and wild-type arm in each subgroup. Moreover, in each group, children and adults were analyzed. The main endpoint was OS, defined as the period from the randomization date to the date of death. Secondary endpoints were PFS, defined as the period from the randomization date to the date when disease progression (or death) was observed. Results regarding OS were expressed as HR with 95\% CI, because it was the only summary statistic that allowed for both censoring and time to an event $[34,35]$. The HRs and 95\% CIs for the available data were calculated to identify potential correlations with overall survival in the two groups by use of the method reported by Tierney et al. [36]. An HR $<1$ means a lower rate of events in the mutations arm.

Statistical analysis was carried out by Review Manager Version 5.3 software provided by the Cochrane Collaboration. Heterogeneity was calculated by application of the Q-statistic and the I2 statistic. If the $Q$ statistic $P$ value $>0.1$, the HRs were pooled according to a fixed-effect model (Mantel-Haenszel). Otherwise, a random-effect model (DerSimonian and Laird) was selected. For I2, values of $25 \%$ to $<50 \%$ were considered small, $50 \%$ to $<75 \%$ were considered medium, and $\geq 75 \%$ were considered large [37].

\section{Recognition of relevant researches}

A total of 645 reports were retrieved when the electronic screening job was finished. After abstract review, 615 articles were excluded and 28 full-text articles remained. Afterward, 10 articles were eliminated for the following reasons: Six articles did not include NOTCH1 or FBXW7 mutation in their studies. Two articles did not analyze OS or EFS. Two articles were about the same trails in different publications. Eventually, 18 studies were eligible. The flow is shown in Supplementary Figure 1.

\section{ACKNOWLEDGMENTS AND FUNDING}

This work was supported by the Science and Technology Planning Project of Guangdong Province, China [NO. Z012B031800382; NO. 2014A020212098] and National Natural Science Foundation of China [NO. 81401908].

\section{CONFLICTS OF INTEREST}

The authors report no conflicts of interest in this work.

\section{REFERENCES}

1. Pui CH, Relling MV, Downing JR. Acute lymphoblastic leukemia. N Engl J Med. 2004; 15:1535-1548.

2. Pui CH, Robison LL, Look AT. Acute lymphoblastic leukaemia. Lancet. 2008; 9617:1030-1043.

3. Weng AP, Ferrando AA, Lee W, Morris JP 4th, Silverman LB, Sanchez-Irizarry C, Blacklow SC, Look AT, Aster JC. Activating mutations of NOTCH1 in human T cell acute lymphoblastic leukemia. Science. 2004; 5694:269-271.

4. Grabher C, von Boehmer H, Look AT. Notch 1 activation in the molecular pathogenesis of T-cell acute lymphoblastic leukaemia. Nat Rev Cancer. 2006; 5:347-359.

5. Tosello V, Ferrando AA. The NOTCH signaling pathway: role in the pathogenesis of T-cell acute lymphoblastic leukemia and implication for therapy. Ther Adv Hematol. 2013; 3:199-210.

6. Demarest RM, Ratti F, Capobianco AJ. It's T-ALL about Notch. Oncogene. 2008; 38:5082-5091.

7. Tetzlaff MT, Yu W, Li M, Zhang P, Finegold M, Mahon K, Harper JW, Schwartz RJ, Elledge SJ. Defective cardiovascular development and elevated cyclin E, Notch proteins in mice lacking the Fbw7 F-box protein. Proc Natl Acad Sci U S A. 2004; 10:3338-3345.

8. Van Vlierberghe P, Ferrando A. The molecular basis of T cell acute lymphoblastic leukemia. J Clin Invest. 2012; 10:3398-3406.

9. Bonn BR, Rohde M, Zimmermann M, Krieger D, Oschlies I, Niggli F, Wrobel G, Attarbaschi A, Escherich G, Klapper W, Reiter A, Burkhardt B. Incidence and prognostic relevance of genetic variations in T-cell lymphoblastic lymphoma in childhood and adolescence. Blood. 2013; 16:3153-3160.

10. Clappier E, Collette S, Grardel N, Girard S, Suarez L, Brunie G, Kaltenbach S, Yakouben K, Mazingue F, Robert A, Boutard P, Plantaz D, Rohrlich P, et al. NOTCH1 and FBXW7 mutations have a favorable impact on early response to treatment, but not on outcome, in children with T-cell acute lymphoblastic leukemia (T-ALL) treated on EORTC trials 58881 and 58951. Leukemia. 2010; 12:2023-2031. 
11. Erbilgin Y, Sayitoglu M, Hatirnaz O, Dogru O, Akcay A, Tuysuz G, Celkan T, Aydogan G, Salcioglu Z, Timur C, Yuksel-Soycan L, Ure U, Anak S, et al. Prognostic significance of NOTCH1 and FBXW7 mutations in pediatric T-ALL. Dis Markers. 2010; 6:353-360.

12. Fogelstrand L, Staffas A, Wasslavik C, Sjogren H, Soderhall S, Frost BM, Forestier E, Degerman S, Behrendtz M, Heldrup J, Karrman K, Johansson B, Heyman M, et al. Prognostic implications of mutations in NOTCH1 and FBXW7 in childhood T-ALL treated according to the NOPHO ALL-1992 and ALL2000 protocols. Pediatr Blood Cancer. 2014; 3:424 430.

13. Jenkinson S, Koo K, Mansour MR, Goulden N, Vora A, Mitchell C, Wade R, Richards S, Hancock J, Moorman AV, Linch DC, Gale RE. Impact of NOTCH1/FBXW7 mutations on outcome in pediatric T-cell acute lymphoblastic leukemia patients treated on the MRC UKALL 2003 trial. Leukemia. 2013; 1:41-47.

14. Ben Abdelali R, Asnafi V, Leguay T, Boissel N, Buzyn A, Chevallier P, Thomas X, Lepretre S, Huguet F, Vey N, Escoffre-Barbe M, Tavernier E, Reman O, et al. Pediatricinspired intensified therapy of adult T-ALL reveals the favorable outcome of NOTCH1/FBXW7 mutations, but not of low ERG/BAALC expression: a GRAALL study. Blood. 2011; 19:5099-5107.

15. Baldus CD, Thibaut J, Goekbuget N, Stroux A, Schlee C, Mossner M, Burmeister T, Schwartz S, Bloomfield CD, Hoelzer D, Thiel E, Hofmann WK. Prognostic implications of NOTCH1 and FBXW7 mutations in adult acute T-lymphoblastic leukemia. Haematologica. 2009; 10:1383-1390.

16. Mansour MR, Sulis ML, Duke V, Foroni L, Jenkinson S, Koo K, Allen CG, Gale RE, Buck G, Richards S, Paietta E, Rowe JM, Tallman MS, et al. Prognostic implications of NOTCH1 and FBXW7 mutations in adults with T-cell acute lymphoblastic leukemia treated on the MRC UKALLXII/ ECOG E2993 protocol. J Clin Oncol. 2009; 26:4352-4356.

17. Mansur MB, Hassan R, Barbosa TC, Splendore A, Jotta PY, Yunes JA, Wiemels JL, Pombo-de-Oliveira MS. Impact of complex NOTCH1 mutations on survival in paediatric T-cell leukaemia. BMC Cancer. 2012:9.

18. Trinquand A, Tanguy-Schmidt A, Ben Abdelali R, Lambert J, Beldjord K, Lengline E, De Gunzburg N, PayetBornet D, Lhermitte L, Mossafa H, Lheritier V, Bond J, Huguet F, et al. Toward a NOTCH1/FBXW7/RAS/PTENbased oncogenetic risk classification of adult T-cell acute lymphoblastic leukemia: a Group for Research in Adult Acute Lymphoblastic Leukemia study. J Clin Oncol. 2013; 34:4333-4342.

19. Van Vlierberghe $\mathrm{P}$, Ambesi-Impiombato A, De Keersmaecker K, Hadler M, Paietta E, Tallman MS, Rowe JM, Forne C, Rue M, Ferrando AA. Prognostic relevance of integrated genetic profiling in adult T-cell acute lymphoblastic leukemia. Blood. 2013; 1:74-82.

20. Mullighan CG. Mutations of NOTCH1, FBXW7, and prognosis in T-lineage acute lymphoblastic leukemia. Haematologica. 2009; 10:1338-1340.
21. Park MJ, Taki T, Oda M, Watanabe T, Yumura-Yagi K, Kobayashi R, Suzuki N, Hara J, Horibe K, Hayashi Y. FBXW7 and NOTCH1 mutations in childhood $\mathrm{T}$ cell acute lymphoblastic leukaemia and $\mathrm{T}$ cell non-Hodgkin lymphoma. Br J Haematol. 2009; 2:198-206.

22. Breit S, Stanulla M, Flohr T, Schrappe M, Ludwig WD, Tolle G, Happich M, Muckenthaler MU, Kulozik AE. Activating NOTCH1 mutations predict favorable early treatment response and long-term outcome in childhood precursor T-cell lymphoblastic leukemia. Blood. 2006; 4:1151-1157.

23. Gao C, Liu SG, Zhang RD, Li WJ, Zhao XX, Cui L, Wu MY, Zheng HY, Li ZG. NOTCH1 mutations are associated with favourable long-term prognosis in paediatric T-cell acute lymphoblastic leukaemia: a retrospective study of patients treated on BCH-2003 and CCLG-2008 protocol in China. Br J Haematol. 2014; 2:221-228.

24. Huh HJ, Lee SH, Yoo KH, Sung KW, Koo HH, Jang JH, Kim K, Kim SJ, Kim WS, Jung CW, Lee KO, Kim SH, Kim HJ. Gene mutation profiles and prognostic implications in Korean patients with T-lymphoblastic leukemia. Ann Hematol. 2013; 5:635-644.

25. Kox C, Zimmermann M, Stanulla M, Leible S, Schrappe M, Ludwig WD, Koehler R, Tolle G, Bandapalli OR, Breit S, Muckenthaler MU, Kulozik AE. The favorable effect of activating NOTCH1 receptor mutations on long-term outcome in T-ALL patients treated on the ALL-BFM 2000 protocol can be separated from FBXW7 loss of function. Leukemia. 2010; 12:2005-2013.

26. Zuurbier L, Homminga I, Calvert V, te Winkel ML, Buijs-Gladdines JG, Kooi C, Smits WK, Sonneveld E, Veerman AJ, Kamps WA, Horstmann M, Petricoin EF 3rd, Pieters R, et al. NOTCH1 and/or FBXW7 mutations predict for initial good prednisone response but not for improved outcome in pediatric T-cell acute lymphoblastic leukemia patients treated on DCOG or COALL protocols. Leukemia. 2010; 12:2014-2022.

27. Asnafi V, Buzyn A, Le Noir S, Baleydier F, Simon A, Beldjord K, Reman O, Witz F, Fagot T, Tavernier E, Turlure P, Leguay T, Huguet F, et al. NOTCH1/FBXW7 mutation identifies a large subgroup with favorable outcome in adult T-cell acute lymphoblastic leukemia (T-ALL): a Group for Research on Adult Acute Lymphoblastic Leukemia (GRAALL) study. Blood. 2009; 17:3918-3924.

28. Callens C, Baleydier F, Lengline E, Ben Abdelali R, Petit A, Villarese P, Cieslak A, Minard-Colin V, Rullier A, Moreau A, Baruchel A, Schmitt C, Asnafi V, et al. Clinical impact of NOTCH1 and/or FBXW7 mutations, FLASH deletion, and TCR status in pediatric T-cell lymphoblastic lymphoma. J Clin Oncol. 2012; 16:1966-1973.

29. Ma J, Wu M. The indicative effect of Notch1 expression for the prognosis of T-cell acute lymphocytic leukemia: a systematic review. Mol Biol Rep. 2012; 5:6095-6100.

30. Zhu YM, Zhao WL, Fu JF, Shi JY, Pan Q, Hu J, Gao XD, Chen B, Li JM, Xiong SM, Gu LJ, Tang JY, Liang H, et al. 
NOTCH1 mutations in T-cell acute lymphoblastic leukemia: prognostic significance and implication in multifactorial leukemogenesis. Clin Cancer Res. 2006; 10:3043-3049.

31. Higgins JP. Commentary: Heterogeneity in meta-analysis should be expected and appropriately quantified. Int J Epidemiol. 2008; 5:1158-1160.

32. Parmar MK, Torri V, Stewart L. Extracting summary statistics to perform meta-analyses of the published literature for survival endpoints. Stat Med. 1998; 24:2815-2834.

33. Jadad AR, Moore RA, Carroll D, Jenkinson C, Reynolds DJ, Gavaghan DJ, McQuay HJ. Assessing the quality of reports of randomized clinical trials: is blinding necessary? Control Clin Trials. 1996; 1:1-12.
34. Williamson PR, Smith CT, Hutton JL, Marson AG. Aggregate data meta-analysis with time-to-event outcomes. Stat Med. 2002; 22:3337-3351.

35. Smith CT, Williamson PR, Marson AG. An overview of methods and empirical comparison of aggregate data and individual patient data results for investigating heterogeneity in meta-analysis of time-to-event outcomes. J Eval Clin Pract. 2005; 5:468-478.

36. Tierney JF, Stewart LA, Ghersi D, Burdett S, Sydes MR. Practical methods for incorporating summary time-to-event data into meta-analysis. Trials. 2007:16.

37. Higgins JP, Thompson SG. Quantifying heterogeneity in a meta-analysis. Stat Med. 2002; 11:1539-1558. 